\title{
Ignatian Pedagogy for Social Entrepreneurship: Twelve Years Helping 500 Social and Environmental Entrepreneurs Validates the GSBI Methodology
}

\author{
Keith Douglass Warner ${ }^{1 *}$, Andrew Lieberman ${ }^{1}$, Pamela Roussos ${ }^{1}$
}

\begin{abstract}
In frontier economies, social entrepreneurship has emerged as a successful strategy to pursue sustainable development goals. By creatively blending business strategy, technology innovation and a deep understanding of customer need, social enterprises provide a pathway out of poverty, an alternative to private charity and government aid. Social entrepreneurs are developing strategies to make available distributed energy products, clean cooking and clean water technologies, and sustainable livelihoods. Social entrepreneurship is a pro-poor economic development strategy that promotes the common good. Many social entrepreneurs describe their work with terms like "calling" or "moral purpose" or "vocation," harkening the emphasis in the Ignatian spiritual exercises on "making an election."
\end{abstract}

Launched in 2003, the Global Social Benefit Institute (GSBI), at Santa Clara University was and is a pioneer in the field of social enterprise capacity development. Originally conceived as a social enterprise incubator, GSBI now offers a diversified portfolio of programs. The GSBI has worked with more than 340 social enterprises. These operate in more than 60 countries, and have raised US\$96 million in funding. The GSBI does not deploy explicit religious language, however, its educational philosophy is shaped by Jesuit educational values. It recruits and selects social entrepreneurs who serve the poor, and places them in stage-appropriate programs to help them grow and serve more people. The GSBI provides a structured curriculum combined with customized mentoring by experienced Silicon Valley executives. This follows very closely the notion of cura personalis, the personalized spiritual accompaniment provided by Jesuit spiritual directors, and is consistent with classic Jesuit educational philosophy. This pedagogy of accompaniment provides optimal support for people to make progress toward their divinely gifted potential.

Perhaps most important of all, Ignatian spirituality and the social entrepreneurship movement share an inspiring moral imagination. Both are unreasonable in their insistence that more can be done to alleviate the unjust suffering of the poor. The GSBI bridges these two realms, exchanging the inspiration and practical can-do of both social entrepreneurs and Ignatian pedagogy. The social entrepreneurship movement benefits from GSBI's pedagogical approach, and Jesuit Catholic higher education benefits from collaborating with this practical social justice movement.

Keywords: Social entrepreneurship; Ignatian pedagogy; vocational discernment; executive mentoring; social justice; sustainable development

$21^{\text {st }}$ International Association of Jesuit Business Schools (IAJBS)

$18^{\text {th }}$ Colleagues in Jesuit Business Education (CJBE)

\section{Introduction}

Social entrepreneurship demonstrates a new way to apply business principles to address social needs (Elkington \& Hartigan, 2008; Kickul \& Lyons, 2012). It proposes a fresh solution methodology for addressing the needs of the poor and a pathway to sustainable, propoor economic development. In short, social entrepreneurship can the global poor participate in economic life as envisioned by Pope Francis. This paper will present the example of the Global Social Benefit Institute (GSBI*) at Santa Clara University, highlighting the Ignatian values and pedagogies that shape it, and are conveyed by its programs.It will describe the vocation of social entrepreneurs, the importance of mentoring relationships as a form of professional accompaniment, and the role of imagination in this field. Each section will discuss social entrepreneurs, the practices of GSBI, and the role of Ignatian pedagogy. Fostering social entrepreneurship can help Jesuit Catholic universities extend their mission, their "social project" (O’Malley, 1993).

\section{The vocation of social entrepreneurship}

Gregory Dees (Dees, 2001) definition of social entrepreneurs outlines the project of this social change movement: "Social entrepreneurs play the role of change agents in the social sector by adopting a mission to create and sustain social value (not just private value); recognizing and relentlessly pursuing new opportunities to serve that mission; engaging in a process of continuous innovation, adaptation, and learning; acting boldly without being limited by resources currently in hand; and exhibiting a heightened sense of accountability to the constituencies served and for the outcomes created." When applied to the Global South, or frontier economies, this definition illuminates the importance of social value creation, in other words, the promotion of an inclusive economy for the common good.

Social entrepreneurs work to change the status quo of social injustices. They tackle some of humanity's greatest social problems, and launch businesses to create markets that advance the common good.

(1) Miller Center for Social Entrepreneurship, Santa Clara University, CA.

* Corresponding author: kwarner@scu.edu 
They look upon social problems and reimagine them as business opportunities. For this reason they are called unreasonable (Elkington \& Hartigan, 2008). Social entrepreneurship is now a worldwide movement that offers an alternative mode of promoting social justice (Martin \& Osberg, 2007).

Launched in 2003, the Global Social Benefit Institute at Santa Clara University has been a pioneer in the field of social enterprise capacity development (Lieberman, Roussos, \& Warner, 2015). It was designed to draw from the technology innovation and entrepreneurial spirit of Silicon Valley (home of Santa Clara) to serve social entrepreneurs by building their capacity to address sustainable development goals. Originally conceived as a social enterprise incubator, the GSBI has diversified its portfolio of program offerings, and now serves start up, early stage, and mid-stage enterprises with a blend of structured curriculum and customized mentoring. With activities and experimentation that has spanned more than a decade, GSBI has validated its capacity development methodology.

The GSBI is the flagship program of the Miller Center for Social Entrepreneurship, one of three centers of distinction at Santa Clara University. These centers were created to advance the university's mission by linking the academic life of the campus with communities of moral concern and ethical practice. The Miller Center's mission statement reflects the fusion of Silicon Valley acumen and the Jesuit ethos: "Accelerate global, innovation-based entrepreneurship in service to humanity." The Miller Center advances its mission along three axes:

- The GSBI program mentors and educates social entrepreneurs, helping them to enhance their business plans and thus making them more fundable and scalable.

- The Impact Capital program creates innovative financial inclusion vehicles to unlock capital flows and prepare social entrepreneurs for investment readiness.

- The Education and Action Research program anchors the Center firmly in the university through classroom and field-based education in social entrepreneurship, by providing transformational social justice learning through the Global Social Benefit Fellowship, and linking social entrepreneurs with on-campus research.

The Miller Center and the GSBI reflect the humanistic values of Jesuit Catholic education (Modras, 2004). Santa Clara University provides a rich set of intellectual and spiritual resources, and fertile institutional context for building capacity of social enterprises. The university draws upon its Jesuit Catholic tradition, emphasizing humanistic education and the development of a personal moral vision for service to others, especially the poor and marginalized, aligning education with social engagement for justice. GSBI advances the university's mission to provide education to foster a humane, just, and sustainable world. It conveys the social project of Jesuit Catholic education in a concrete and contemporary way (Kolvenbach, 2000).

Based on its experience with the more than 500 social entrepreneurs who have completed its programs since 2003, GSBI has honed an effective and practical methodology for social entrepreneurship. Factors that differentiate the GSBI model from other capacity development programs include:

- A selection process that identifies high-potential social enterprise leaders whose organizations are able to benefit from a GSBI program;

- Stage-appropriate educational programs that provide highly relevant capacity development, enabling social enterprises to develop and present effective, fundable business models while also measuring social impact;

- Customized mentoring by experienced Silicon Valley executives working with structured curriculum to provide coaching, information, tools, and a support network to assist the entrepreneurs in successfully understanding and evolving their businesses;

- A theory of change that leads with an enterprises' vision for social impact and applies Silicon Valley start-up acumen to create a supporting, sustainable operational model.

These factors will be discussed in greater detail below. Metrics show that the lives of more than 107 million people across 60 countries have been positively impacted by these 500 enterprises. At present, $90 \%$ of GSBI alumni remain in business. Of these enterprises, $40 \%$ are scaling, which indicates that their social impact continues to grow in a financially sustainable manner. More than $95 \%$ of participating social entrepreneurs work chiefly in the developing world, a figure due to GSBI's recruitment efforts that are concentrated in there.

The GSBI works with "impact first" social entrepreneurs. A traditional entrepreneur measures success only by reducible financial benefits such as return on investment or profit maximization. A social entrepreneur must pursue social and financial sustainability goals. An applicant to GSBI does not need to identify him- or herself as a social entrepreneur, but does have to prioritize social impact over financial goals.

The social entrepreneurship movement is a social change movement, and many of its most prominent leaders speak of this work in terms such as "calling" or "vocation" or "life work"(Elkington \& Hartigan, 2008). Interviews with social entrepreneurs reveal that many enter this field because of some encounter, direct or indirect, with suffering. This experience redirects the trajectory of their lives, usually to be more other-focused. Social entrepreneurship is not a job, but rather a vocation. Thus, the vocational discernment process followed by social entrepreneurs is quite consistent with vocational discernment as a fundamental orientation of Jesuit education

In 2000, then-Superior General Fr. Peter-Hans Kolvenbach SJ challenged Jesuit higher education in "The Service of Faith and Promotion of Justice in Jesuit Higher Education," an address given at Santa Clara University (Kolvenbach, 2000). He invited Jesuit universities to draw from the strength of its historic educational philosophy but to engage the contemporary world and its needs, and to bring the values of Jesuit education to bear on these, especially the suffering of the poor. Learning at a university should not be insulated from the gritty reality faced by most human beings on our planet, but rather, seek to 
learn with and from them. He argued that the search for knowledge must be complemented by wisdom. Growth in knowledge carries with it a responsibility to act on behalf of others, in love. Education of the whole person is fundamental to Jesuit education. Jesuit universities must help our student grow in their intellect, but also in their affect and their conscience. This demands at least holistic programs, and preferably, integrated programs that help our students become whole persons. Jesuit education is grounded in the Ignatian spiritual exercises. Jesuit universities aspire to prepare leaders who will lead in the best interests of others. Jesuit education is grounded in the civic humanism of the renaissance, and thus, seeks to foster global citizenship as a core educational value in the $21^{\text {st }}$ century.

The long-time president of Santa Clara, Fr. Paul Locatelli SJ, challenged the Santa Clara campus community to draw from Silicon Valley expertise to engage the needs of the global human family (Locatelli, 2002). The GSBI program emerged in 2003 from this favorable institutional context. The vision of Jesuit education and the social enterprise movement share a striking ethical coherence, and at their intersection, GSBI has developed as a practice-based learning laboratory for scaling social impact.

The GSBI was conceived by three Santa Clara University business school faculty (James Koch, Albert Bruno and Eric Carlson) who saw the potential of appropriate, frugal technologies to help foster appropriate economic development in the Global South, but needed business models to facilitate organizational development. Business school faculty members have served as academic advisors to GSBI throughout its history.

\section{Ignatian pedagogies for social entrepreneurs}

The Miller Center believes that innovation and entrepreneurship provide a path out of poverty. This belief stems from in part from its Silicon Valley ethos, but also from the Ignatian tradition of humanistic education, dating back to the founding of the first school founded by the Society of Jesus in 1543 (O’Malley, 1993). The earliest Jesuit schools were innovative in several ways and set the pattern for one of the most successful networks of Catholic higher education institutions. First, they provided education for everyone (not only clerics) focusing on the emerging urban professional class. Second, they brought an age (or stage) appropriate curricula. Few prior schools had an ordered, stepwise approach to presenting educational material. In most other schools, students of all ages and developmental stages were all in the same classroom. Third, the classes were kept small enough to provide individual attention. The (Jesuit) teachers were expected to know their students - and their needs - on an individual basis. The teacher is not only be an instructor, but also to serve as a trusted advisor, a mentor. The Santa Clara University faculty who founded GSBI did not explicitly reference the Ignatian tradition of humanistic education, but they were influenced by their decades of (cumulative) experience teaching at a Jesuit university, and its pedagogical culture. These educational values have shaped the development of GSBI.

\section{Providing programs that meet the needs of social entrepreneurs}

The GSBI selects candidates that are most likely to benefit from a GSBI program, those who recognize their organization needs help in order to grow. The ideal candidate has launched or operates an organization that places greater emphasis on social impact than on financial return. Such candidates must also want to expand the scale of their social impact. The candidate must be committed to creating an organization that is capable of attaining financial sustainability, while also reaching increasingly larger numbers of beneficiaries, and systematically measuring the organization's social impact.

For its first nine years, the GSBI provided one common program for entrepreneurs regardless of the developmental stage of their organization. In 2012, GSBI created a Social Enterprise Stage Assessment Tool to evaluate the educational needs of social entrepreneurs, and to guide the segmentation of its educational programs. This tool was shaped by the analysis provided by the Monitor Group's publication, Blueprint to Scale (Koh, Karamchandani, \& Katz, 2012), which outlines four development stages in the lifecycle of an enterprise:

- Blueprint: Developing the idea for the future business

- Validate: Testing and refining the business model, and the assumptions upon which it is built

- Prepare: Developing the internal capacity of the enterprise to grow and receive investment

- Scale: Expand the reach of the enterprise to deliver new products or reach customers in new geographic regions

The Social Entrepreneurship Stage Assessment Tool clarifies how enterprises at each stage have common characteristics despite having distinct needs (such as different capital requirements) compared with enterprises at other stages. These stage characteristics are grouped according to the five content areas drawn from the GSBI program curriculum. These content areas include business and impact models, marketing and sales, operations, management and team, and financials and investment requirement.

The Social Enterprise Stage Assessment Tool guides the GSBI team through the evaluation of applicants each cycle, but also informs the creation of stage-appropriate curriculum that targets a different stage of the social enterprise lifecycle. Early-stage social enterprises (operating at the Blueprint and Validate stages) are served by the GSBI Boost and Online programs. These programs help social entrepreneurs focus on developing their social impact model and supporting it with a scalable business model. The social impact model refers to how the enterprise creates a positive impact on the lives of its beneficiaries, for example, by selling villagers safe drinking water from village kiosks, reducing the yearly incidence of water-borne illness and resulting economic losses from medical bills and lost wages. The business model would explain issues such as who owns and operates the kiosks (the enterprise or a micro-entrepreneur in the village), how much capital is required to open each new kiosk, and whether the customers pay per unit of water or through a subscription model. 
During this stage, GSBI's efforts focus on helping the entrepreneur tightly integrate the business model and impact model. The most obvious way to do this is to have the beneficiary pay part or all of the costs of the product or service as opposed to subsidizing through donations. However, other valid social enterprise business models models support activities in which the customer is someone other than the end beneficiary.

More mature enterprises (working through the Prepare stage) are served by the GSBI Accelerator program. These enterprise cohorts come into the program with proven impact and business models. The Accelerator program focuses on operational excellence and becoming investment-ready. In other words, the enterprise is better equipped to raise investment for scaling. Operational excellence is defined as having an organization with a management team and documented operations processes in place so that the organization runs efficiently, effectively, and predictably.

Building upon the successful structure of the original GSBI that combines online and in-residence work, the GSBI Accelerator was launched in 2013. It is a ten-month, online program built around a nine-day, in-residence workshop. This program selects social enterprises at the third stage, Prepare, and helps them advance to the Scale stage. Mentors are assigned to each social enterprise. The focus of both mentors and participants is to ready the enterprises for the investment process and addresses any remaining gaps or missing organizational components that might impede their organizations from scaling.

Having shepherded more than 20 discrete groups of social enterprises through GSBI programs, the ideal cohort size appears to be between 15 to 20 participating enterprises. This cohort size is large enough to allow for student co-learning via similar sector, geography, or business models, yet small enough for entrepreneurs and the GSBI team to receive personal attention. All GSBI programs guide the social entrepreneur to become investment-ready as appropriate for their assessed stage. In early stages, gifts and grants may be appropriate forms of investment. At later stages, investments may come in the form of debt, equity, and/or structured exits (Dichter, Katz, Koh, \& Karamchandani, 2013).

Central to GSBI's methodology for moving an enterprise along this path to scale is the application of executive mentorship combined with structured curriculum such that entrepreneurs can immediately apply new concepts to their enterprise's business model. The curriculum teaches certain key concepts for a given topic, such as social impact metrics or target-market segmentation. It also provides a template and examples of each concept. After reviewing the curriculum, whether it is in person, via webinar, or through a video, the entrepreneur then proceeds to develop the corresponding part of their business plan. Mentors provide personalized guidance and feedback. They make the curriculum come alive.

Each program delivers this methodology in a distinct format, tailored to provide the most value to the enterprises as efficiently and effectively as possible. As mentioned earlier, GSBI in its earlier years did not differentiate its offerings according to organizational lifecycle stages, since the pool of social enterprises was much smaller and generally earlier stage. It is a measure of the evolution of the social enterprise field and GSBI's experience, growth, and learning process that it does so now.

\section{Customized mentoring by Silicon Valley executives}

Vital to GSBI's effectiveness is the customized involvement of a cadre of more than eighty volunteer mentors, all with relevant professional experience and Silicon Valley acumen. The GSBI screens and selects executive volunteers with expertise, and matches them with social entrepreneurs in the program. This acumen can be defined as the combination of mindset and skill that fosters rapid innovation and growth, agile responsiveness to customer/market needs, strength through specialization, and a willingness to embrace failure's tough lessons to achieve future success.

These professional volunteers draw from their own backgrounds in myriad ways to help entrepreneurs bring forward new solutions based on innovative thinking and creative business models. The mentors are experts at starting companies, building teams, and raising investment funds. Through dialog, they personalize the curriculum for the entrepreneur they are working with, connecting their real-world experience with the entrepreneur's business and the learning modules. Mentors describe their participation in GSBI programs as a natural fit and a deeply rewarding experience.

In addition to their business acumen, the mentors are selected based on empathy and values. They, too, undergo a formation process to review the traits and skills GSBI has identified most likely to lead to successful mentoring relationships. An expected outcome is for mentors to act as trusted advisors, able to coach the entrepreneurs, challenge assumptions, validate business models, inspire continued iterations, and support the completion of strategic and operational plans for sustainably scaling each enterprise.

Mentoring interactions last for a minimum of the program duration, but often continue much longer. GSBI's Online and Accelerator programs, spanning a six-month and ten-month commitment respectively, involve weekly mentor-entrepreneur telephone or Skype calls and often lead to the formation of much deeper bonds. While not tracked formally, there have been a number of cases of mentors providing ongoing support to an entrepreneur years after the program ends and, in some cases, even joining the entrepreneur's board of directors.

The social entrepreneurs who have completed the program consistently rate the significant contribution of mentors from the Silicon Valley business community as the most valuable part of the GSBI experience. In the 2013 and 2014 Accelerator program, 96\% of participants agreed that the mentoring they received allowed them to be successful in the program, and $100 \%$ of the participants plan to stay in touch with their mentors. Social entrepreneur participants in GSBI cite as especially memorable specifics such as: 
- Mentors' constructive feedback on the learning modules;

- Their individualized discussions with social entrepreneurs as they work to refine their business plans;

- The mentors' support and advice in response to the unique challenges and endeavors the entrepreneur is facing on any given day.

Mentors donate their time. Mentors cite the rewards of personal inspiration and renewed purpose that occur when giving back to their community and working with social entrepreneurs. Whether an organization's social impact targets literacy, access to safe drinking water, economic participation for new demographic sectors, basic healthcare services, the GSBI mentors bring hands-on knowledge of building enterprises to the social entrepreneur's efforts to grow.

Every GSBI mentor operates as a "trusted advisor." The GSBI staff chooses mentors who, through their education, background, and career, have experience in start-up enterprises and possess knowledge of business planning fundamentals and have experienced the challenges of executing those plans. They also share in the Santa Clara University mission to create a more just, humane, and sustainable world. While mentors, in most cases, may not have personal experience with the country in which their mentees work, many have international business experience and all are aware and respectful that cultural, legal, and market environments are often vastly different from what the mentor is accustomed to.

The primary role of the mentor is not to provide the answers. Rather, it is to ask the right questions and help the entrepreneur find the right answers. In certain cases, mentors may act in a consulting capacity, giving expert advice on particular areas of business or technology if they possess expertise in those areas. It is important for social entrepreneurs to find other mentors for long-term support, particularly in their own region where such individuals would be more readily available for face-to-face work. One of the tasks of GSBI mentors is to challenge the social entrepreneurs to develop a circle of support. By tapping into the expertise of board members, advisors, mentors, and other social entrepreneurs, program participants can fill in the gaps of skills, knowledge, and talent that might exist within their own organizations.

As the program description above narrates, the Ignatian humanism that has grounded Jesuit education for centuries informs the GSBI programs. A great deal of effort is made to match the needs of the learner with stepwise curriculum. GSBI depends upon personalized mentoring; the programs would not work with structured curriculum alone. Although GSBI does not use the term cura personalis, it follows this practical wisdom. One of the founders of GSBI describes this as the practice of "accompaniment." This educational approach has been adopted not from a priori value commitments, but rather for pragmatic reasons. It successfully helps social enterprises enhance their ability to serve the poor.

\section{Jesuit higher education can and should accompany the social enterprise movement}

Fr. Adolfo Nicolas SJ succeeded Fr. Peter-Hans Kolvenbach SJ as Superior General of the Jesuits. In 2010 Nicolas built upon his predecessor's vision with a major address titled "Depth, universality, and learned ministry: Challenges to Jesuit higher education today" (Nicolás, 2011). Nicolas devoted considerable attention to the centrality of imagination in the Ignatian tradition, and in Jesuit higher education, especially in the formation of an ethical response to what he calls "the globalization of superficiality." He tied the practice of imagination to the contemplation on the mysteries of the life of Jesus in the Ignatian spiritual exercises. In this practice, the seeker actively remembers experiences of one's own life in light of the example of Jesus. The seeker allows his or her understanding of the life of Christ - and own experience of faith -- to be dis-assembled, selectively attended to, and then reassembled. This new mosaic of understanding and experience has the power to prompt a re-imagining, a re-visioning of what God is calling one to do, of what new choices are possible in light of the love of God. In the language of the exercises, their purpose is to "make an election." Elements of these experiences are common across diverse Catholic spiritualities, and shapes the Catholic imagination (Greeley, 2000). The Ignatian spiritual exercises propose a specific form, a specialized method of cultivating these experiences (Modras, 2004). Fr. Nicolas's address challenged to Jesuit educators to draw upon these Ignatian practices to formulate an ethical and religious response to globalization and its negative impacts.

This whole process can also be described as exercise of the moral imagination. Mark Johnson defines moral imagination as "the ability to imaginatively discern possibilities for making good choices, and to envision the potential good outcomes that might result" (Johnson, 1994). Many accounts of social entrepreneurs highlight the role of the imagination, and the ability to creatively envision pathways to positive social futures that are imperceptible to most people. Social entrepreneurship as a movement celebrates its moral imagination. The unreasonableness of social entrepreneurs reflects a heroic leadership as articulated by Chris Lowney in "Heroic Leadership" (Lowney, 2003).

Over the past years, the Miller Center has fashioned a mission and vision that integrates education and action research with GSBI social enterprise capacity development. The GSBI now coordinates its candidate selection and training closely with our impact investors, and the Global Social Benefit Fellowship creates student action research projects to serve the Center's social enterprise partners. The Miller Center and GSBI provide enhanced international recognition for the university, and learning opportunities for students and faculty interested in global social enterprise work. The Miller Center's strength in social entrepreneurship as a strategy to address problems at the intersection of poverty, climate change, the empowerment of women, and impact measurement reflects SCU's innovation and leadership in addressing global social challenges. The Center's understanding of campus engagement is to inform the educational and research mission of the university, so that the university can realize its strategic goal of fostering innovation and entrepreneurship in service of humanity. 
The social enterprise movement is of broad interest to Santa Clara University faculty and students. GSBI social enterprises serve as outstanding case studies for university courses. GSBI social enterprises host student research teams through a dedicated fellowship program. This offering facilitates undergraduate learning via real-world social enterprises and, unlike traditional service learning, requires students to engage in practical "action research," developing analytical tools and reports useful to the host enterprise.

The Miller Center and GSBI aspire to help Jesuit higher education globally to collaborate with the social entrepreneurship movement. From 2007 to 2009, several Jesuit and other mission-aligned universities sent representatives to study early versions of the GSBI curriculum and observe the in-residence portion. They returned to their host institutions to develop their own social enterprise capacity development programs. A majority of these observers came from Jesuit or Catholic universities-again, sharing the value of linking knowledge with practical application in service to the poor.

In 2010, GSBI convened a gathering and launched the GSBI Network to share curriculum, methodology, best practices, and other resources for launching and operating social enterprise incubators and accelerators. In this way, the expertise that has been gained by running GSBI for more than 12 years is now being extended to others, enabling them to strengthen social entrepreneurs locally while serving the broader social impact movement. The GSBI Network now includes 23 partners, 9 stand-alone social enterprise incubators and 14 university partners. Ten of these are Catholic and 9 of these Jesuit in their tradition. The incubation, acceleration, and education projects at these schools have great potential to serve as bridges between the social enterprise movement, Ignatian pedagogy, and a Catholic moral imagination.

\section{Conclusion}

This paper has described the GSBI methodology and demonstrated the shared moral vision of the social entrepreneurship movement and Ignatian pedagogy. By design and intention, the GSBI bridges these two realms, exchanging the inspiration and practical can-do of both social entrepreneurs and Jesuit higher education. The Santa Clara University faculty who founded GSBI did not explicitly reference the Ignatian tradition of humanistic education, but its educational values shaped the development of the GSBI. Its educational philosophy reflects the influence of Jesuit spirituality and the practical experience of helping social enterprises enhance their ability to serve the poor. This paper has outlined the vocation vision of social entrepreneurs, the importance of stage-appropriate educational programs, and the value of mentoring relationships as a form of professional accompaniment. The social entrepreneurship movement and Jesuit higher education share a remarkable coherence in their moral vision. Ignatian pedagogy seeks to open up the vocational discernment and moral imagination of the students at Jesuit schools, and the social entrepreneurship movement believes that through practical, enterprise-scale action, economic justice can be promoted.

\section{Acknowledgements}

Andrew Lieberman wrote the sections on the GSBI methodology, with help from Pamela Roussos. Keith Douglass Warner OFM wrote the sections on Ignatian pedgagogy and social justice.

\section{References}

Dees, J. G. (2001). The Meaning of "Social Entrepreneurship". http://www.caseatduke.org/documents/dees_se.pdf.

Dichter, S., Katz, R., Koh, H., \& Karamchandani, A. (2013). Closing the pioneer gap. Stanford Social Innovation Review, 11(1), 36-43.

Elkington, J., \& Hartigan, P. (2008). The power of unreasonable people: how social entrepreneurs create markets that change the world: Harvard Business Press.

Greeley, A. (2000). The Catholic Imagination. Berkeley: University of California Press.

Johnson, M. (1994). Moral imagination: Implications of cognitive science for ethics: University of Chicago Press.

Kickul, J., \& Lyons, T. (2012). Understanding social entrepreneurship: The relentless pursuit of mission in an ever changing world: Routledge.

Koh, H., Karamchandani, A., \& Katz, R. (2012). From Blueprint to Scale: The case for philanthropy in impact investing: Monitor Group.

Kolvenbach, S. J., Peter-Hans. (2000). The service of Faith and the Promotion of Justice in American Jesuit Higher Education: Santa Clara University, October 6.

Lieberman, A., Roussos, P., \& Warner, K. D. (2015). The GSBI Methodology For Social Entrepreneurship: Lessons From 12 Years Of Capacity Development With 365 Social Enterprises.

Locatelli, P. L., S.J. (2002). Education for Globalization. America(May 20), 3-6.

Lowney, C. (2003). Heroic leadership: Best practices from a 450-yearold company that changed the world: Loyola Pr.

Martin, R. L., \& Osberg, S. (2007). Social entrepreneurship: the case for definition. Stanford Social Innovation Review, 5(2), 28-39.

Modras, R. (2004). Ignatian Humanism: A Dynamic Spirituality for the 21st Century. Chicago: Loyola Press.

Nicolás, A., S.J. (2011). Depth, universality, and learned ministry: Challenges to Jesuit higher education today. Conversations on Jesuit Higher Education, 40(1), 5-12.

O’Malley, J. W., SJ. (1993). The First Jesuits. Cambridge: Harvard University Press. 